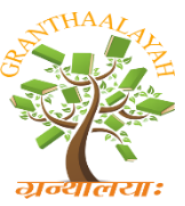

$$
\begin{gathered}
\text { INTERNATIONAL JOURNAL OF RESEARCH - } \\
\text { GRANTHAALAYAH } \\
\text { A knowledge Repository }
\end{gathered}
$$

Science

\title{
THERMAL MODE OF THE BUILDING WITH THE SYSTEM OF REFLECTORS INSTALLED FROM THE NORTHERN SIDE
}

\author{
Sh. B. Imomov ${ }^{1}$, S.I. Xamraev ${ }^{1}$, B.G. Sherkulov ${ }^{1}$ \\ ${ }^{1}$ Имомов Шухрат Боймаматович (Imomov Shukhrat Boymamatovich), Хамраев Сардор \\ Илхомович (Xamraev), Шеркулов Бахром Гуломович (Sherkulov Bakhrom Gulomovich)
}

\begin{abstract}
The heat balance and the temperature regime of the building in the building + reflectors during the period of the minimum arrival of solar radiation (December) and the lowest outside air temperatures (January) in the conditions of Karshi are considered. The obtained results confirm the effectiveness of the application of the building + reflectors system.
\end{abstract}

Keywords: Mode; Building; Northern; Reflectors.

Cite This Article: Sh. B. Imomov, S.I. Xamraev, and B.G. Sherkulov. (2019). "THERMAL MODE OF THE BUILDING WITH THE SYSTEM OF REFLECTORS INSTALLED FROM THE NORTHERN SIDE.” International Journal of Research - Granthaalayah, 7(5), 321-326. https://doi.org/10.29121/granthaalayah.v7.i5.2019.854.

\section{Introduction}

To test the efficiency and predict the temperature regime of the room with a system of flat reflectors, installed on the north side of the building [1], an experimental installation was constructed on the heliopoly of the Karshi State University.

Preliminary studies of the thermal regime of the room with a system of reflectors installed on the north side of the building showed that the high density of solar radiation coming from the reflector system through the northern light hole leads to a significant excess of the comfortable radiation and thermal regimes in the room. To protect the room from the high intensity of solar radiation, a screening heat receiver is installed in front of the northern light-hole. The natural illumination of the room is provided through the south window.

The temperature regime in the room is determined on the basis of the heat balance in the building + reflectors system. 
When preparing the heat balance, the following conditions are accepted:

- interacting elements: internal and external air environment, enclosing structures, a system of flat reflectors;

- the influence of interior items on the heat balance of the premises is not taken into account;

- walls, ceiling ceiling, floor spaces are considered as multi-layered, windows and doors - as single-layer fences;

- the walls, combined with the control and tambour rooms, are considered as multilayered enclosures with air interlayer;

- with respect to the environment, the building is treated as a stand-alone facility.

In general, the heat balance of a room is determined by the equation:

$$
Q_{a b}=Q_{h l}
$$

where $Q_{a b}$ - total absorbed heat of solar radiation entering the room, W; $Q_{h l}$ - total heat loss in the room, W. Total solar radiation that has passed into the room:

$$
Q_{p}=Q_{p 4}+Q_{p 5}
$$

Total solar radiation coming through the window $Q_{p 5}$ and light $Q_{p 3}$, is determined by the formulas:

$$
Q_{p 5}=\left(S_{n p 5}+D_{n p 5}\right) F_{5} ; \quad Q_{n p 3}=\left(S_{n p 3}+D_{n p 3}\right) F_{3} ;
$$

where $S_{p}$ и $D_{p}$ - density of transmitted direct and scattered solar radiation, $\mathrm{W} / \mathrm{m}^{2} ; F_{5}$ and $F_{3}-$ the area of the glazed surface of the window and the light-bearing area, $\mathrm{m}^{2}$.

Direct solar radiation in the lightguard comes from the reflectors:

$$
S_{n p 3}=S_{n p 0}+2 S_{n p 1} \sin \gamma
$$

where $S_{p 0}, S_{p 1}$ - direct solar radiation coming from the middle and right + left reflectors, $\mathrm{W} / \mathrm{m}^{2} ; \gamma$ - angle of incidence of rays on the plane of the heat receiver, deg.

Solar radiation entering the room is absorbed by the internal surfaces and the heat receiver:

$$
Q_{a b 5}=A_{p} Q_{p 5} ; \quad Q_{a b 4}=A_{r} Q_{p 3} ;
$$

where $A_{p}$ - the reduced coefficient of absorption of solar radiation by the internal surfaces of the room; $A_{r}$ - coefficient of absorption of solar radiation by the heat receiver. Total heat loss in the room:

$$
Q_{h l}=Q_{h f}+Q_{a}
$$

where $Q_{h f}-$ heat loss through fences, W; $Q_{s}-$ heat loss by infiltration of air, W. 
Heat loss through fences:

$$
Q_{h f}=K_{p} F_{f e n}\left(t_{b}-t_{H}\right) ;
$$

where $K_{p}$ - reduced coefficient of heat transfer of the fence, $\mathrm{W} /\left(\mathrm{m}^{2} \mathrm{~K}\right) ; F_{\text {огp }}$ - total surface area of the fence, $\mathrm{M}^{2} ; t_{i}, t_{e}$ - temperature of indoor and outdoor air, ${ }^{\circ} \mathrm{S}$.

Heat loss by infiltration - air ventilation

$$
Q_{v}=c_{p} \rho_{B} V_{B}\left(t_{B}-t_{H}\right) ;
$$

where $c_{p}$ - Specific heat of air, $\mathrm{J} /(\mathrm{kg} \mathrm{K}) ; \rho_{b}$ - density of air, $\mathrm{kg} / \mathrm{m}^{3} ; V_{v}$ - volume of ventilated air, $\mathrm{m}^{3} / \mathrm{s}$.

Taking (7) and (8) into account, we reduce (1) to the form:

$$
Q_{a b}=K_{p} F_{f e n}\left(t_{i}-t_{e}\right)+c_{p} \rho V_{v}\left(t_{i}-t_{e}\right) .
$$

Where do we get:

$$
t_{i}=t_{e}+\frac{Q_{a b}}{K_{p} \cdot F_{f e n}+c_{p} \cdot \rho \cdot V_{v}} .
$$

The reduced heat transfer coefficient of the enclosure is determined by the formula:

$$
K_{n p}=\frac{\sum_{i=1}^{n} K_{i} \cdot F_{i}}{F_{o z p}} ;
$$

where $K_{i}$ - heat transfer coefficient $i$ - fencing element, $\mathrm{V} /\left(\mathrm{m}^{2} \mathrm{~K}\right) ; F_{i}$ - surface area of the fence element, $\mathrm{m}^{2} ; i=1,2,3,4,5$-index of fencing elements.

Heat transfer coefficient of fencing elements:

$$
K_{i}=\frac{1}{1 / \alpha_{i i}+R_{i}+1 / \alpha_{e i}}
$$

where $\alpha_{i i}$ and $\alpha_{e i}$ - heat transfer coefficients on the inner and outer surfaces of fencing elements, $\mathrm{V} /\left(\mathrm{m}^{2} \mathrm{~K}\right) ; R_{i}-$ thermal resistance of the fence, $\mathrm{m}^{2} \mathrm{~K} / \mathrm{V}$.

Heat transfer on the surfaces of the enclosure occurs by convection and radiation:

$$
\alpha_{i i}=\alpha_{i c i}+\alpha_{i r i} ; \alpha_{e i}=\alpha_{e c i}+\alpha_{e r i}
$$

where $\alpha_{i c i}$ and $\alpha_{i r i}$ - convective components of heat transfer coefficients, $\mathrm{V} /\left(\mathrm{m}^{2} \mathrm{~K}\right) ; \alpha_{e c i}$ and $\alpha_{e r i}$ radiative emission factors, $\mathrm{V} /\left(\mathrm{m}^{2} \mathrm{~K}\right)$. 
Thermal resistance of fencing:

$$
R_{i}=\sum_{j=1}^{n} \delta_{i j} / \lambda_{i j}
$$

where $\delta_{i j}$-thickness of the fence layer, $\mathrm{m} ; \lambda_{i j}$ - coefficient of thermal conductivity of the material of the fence layer, $\mathrm{W} /(\mathrm{m} \mathrm{K}) . j$ - number of layers in the enclosure.

Coefficient of convective heat transfer on internal surfaces fencing is determined by the formula [2]:

$$
\alpha_{i c i}=1,66 \cdot A \cdot \sqrt[3]{t_{i}-t_{f i i}}
$$

where $t_{f i i}$ - average temperature of the inner surface of the fence, ${ }^{\circ} \mathrm{S} ; A$-coefficient, depending on the location of the surface.

Coefficients of convective heat transfer at the outer surfaces of the enclosure are determined by the formula [3]:

$$
\alpha_{e c i}=6,43+3,57 w ; \quad w \leq 5 \mathrm{~m} / \mathrm{s} ;
$$

where $w$ - wind speed, $\mathrm{m} / \mathrm{s}$.

Coefficients of heat emission by radiation on the inner surfaces of the fence [4]:

$$
\alpha_{i r i}=\sigma \frac{\left(T_{в}+T_{o b i}\right)\left(T_{b}^{2}+T_{o b i}^{2}\right)}{1 / \varepsilon_{\text {oi }}+\left(1 / \varepsilon_{\text {onp }}-1\right) F_{i} /\left(F_{o z p}-F_{i}\right)}
$$

where $\sigma=5,67 \times 10^{-8} \mathrm{~V} /\left(\mathrm{m}^{2} \mathrm{~K}\right)$ - the Stefan-Boltzmann constant; $\varepsilon_{6 i}$ - the degree of blackness of the inner surface of the element of the fence surface; $\varepsilon_{6 n p}$ - reduced degree of blackness of the inner surfaces of the fence; $T_{o в i}$ and $T_{6}-$ absolute temperature of internal surfaces of fencing and air, $\mathrm{K}$. Coefficients of heat emission by radiation on the external surfaces of walls, windows and light holes are determined with respect to the outside air temperature:

$$
\alpha_{H u i}=\sigma \cdot \varepsilon_{\mu i} \cdot\left(T_{H i}+T_{H}\right)\left(T_{H i}^{2}+T_{H}^{2}\right)
$$

where $T_{H i}$-temperature of the outer surface of the fence, $\mathrm{K}$.

The coefficient of heat emission by radiation on the upper surface of the roof of the ceiling is determined with respect to the temperature of the sky [5]

$$
\alpha_{H u 2}=\sigma \cdot \varepsilon_{H 2} \cdot\left(T_{H 2}+T_{o}\right)\left(T_{H 2}^{2}+T_{o}^{2}\right) ;
$$

$T_{H 2}$ - temperature of the outer surface of the roof guard, $\mathrm{K} ; \quad T_{o}=0,0552 T_{H}^{1,5}$ - sky temperature, $\mathrm{K}$. 
The blackened heat receiver, due to the absorption of solar radiation, heats up and transfers heat to the air in the room. Heat transfer from the heat collector occurs from two sides: from the inside (towards the room) and from the outside (towards the window). The temperature of the inner and outer surfaces of the heat receiver is not more than $0.2 \ldots 0.3^{\circ} \mathrm{S}$. Therefore, the temperature on both surfaces of the heat receiver can be assumed to be the same. The temperature of the heat receiver is determined by the temperature of the internal air and the amount of absorbed radiation [5]:

$$
t_{m}=t_{6}+Q n_{24} / \alpha_{m}
$$

where $\alpha_{m}$ - the total heat transfer coefficient on the surfaces of the heat receiver, $\mathrm{V} /\left(\mathrm{m}^{2} \mathrm{~K}\right)$ :

$$
\alpha_{m}=\alpha_{m \varepsilon}+\alpha_{m H}
$$

$\alpha_{m \varepsilon}$ and $\alpha_{m н}-$ heat transfer coefficient on the inner and outer surfaces of the heat sink, $\mathrm{V} /\left(\mathrm{m}^{2} \mathrm{~K}\right)$ :

$$
\alpha_{m в}=\alpha_{\text {твк }}+\alpha_{\text {тви }} ; \quad \alpha_{m н}=\alpha_{\text {тнк }}+\alpha_{\text {тни }} .
$$

The coefficients of heat transfer by convection on the surfaces of the heat receiver are determined by the formula [5]:

$$
\begin{gathered}
N u=0,433(G r \cdot \operatorname{Pr})^{0,267} ; \\
N u=\frac{\alpha_{m \kappa} \cdot l_{m}}{\lambda_{B}} ; G r=\frac{g \cdot \beta \cdot l_{m}^{3}\left(t_{m}-t_{b}\right)}{v_{B}^{2}} ; \quad \operatorname{Pr}=\frac{v_{B}}{a_{B}} ;
\end{gathered}
$$

where $N u, G r, P r-$ Nusselt number, Grasgof, Prandtl; $l_{m}$ - The determining size is the height of the heat receiver, $\mathrm{m} ; g$ - acceleration of gravity, $\mathrm{m} / \mathrm{s}^{2} ; t_{m}$ - temperature of the heat receiver, ${ }^{\circ} \mathrm{C} ; \beta$ - temperature coefficient of air density change, $\mathrm{K}^{-1} ; v_{b}, a_{b}$ - coefficients of kinematic viscosity and thermal diffusivity of air, $\mathrm{m}^{2} / \mathrm{s}$.

The coefficient of heat emission by radiation on the inner surface of the heat receiver is determined with respect to the temperature of the internal air:

$$
\alpha_{m в и}=\sigma \frac{\left(T_{b}+T_{m}\right)\left(T_{s}^{2}+T_{m}^{2}\right)}{1 / \varepsilon_{m}+\left(1 / \varepsilon_{\text {вnp }}-1\right) F_{m} /\left(F_{\text {oгp }}-F_{m}\right)} ;
$$

where $\varepsilon_{m}$ - blackness of the heat receiver surface; $F_{m}$ - surface area of the heat receiver.

The coefficient of heat emission by radiation on the external surface of the heat receiver is determined with respect to the temperature of the inner surface of the glazing

$$
\alpha_{\text {тни }}=\sigma \frac{\left(T_{m}+T_{B 2}\right)\left(T_{m}^{2}+T_{B 2}^{2}\right)}{1 / \varepsilon_{m}+1 / \varepsilon_{c}-1} ;
$$

where $T_{62}$ - temperature of the inner surface of the glazing of the window, $K$; $\varepsilon_{c}$ - the degree of blackness of the glazing surface. 
Equations (1) - (8) determine the heat balance of the building system + reflectors. The accuracy of the calculation of the heat balance depends on the correct determination of the heat transfer coefficients at the fence surfaces (13) - (19), the heat receiver (21) - (26), and the thermophysical characteristics of the fence construction materials. The real heat balance ensures the prediction of the thermal regime (10), (11), (20) the building + reflectors.

For comparison, the values of the arrival of solar radiation in a room through the southern lightprojector with an equivalent area $3 F_{3}: 3-3 F_{3}-Q_{n p 5 B}$ and a wall of the Thrombus falling on a vertical surface; $4-3 F_{3}-Q_{n p 5 \Gamma}$ and falling on the floor and walls in the room. As can be seen, with equal light transmitting surfaces, the influx of solar radiation from the reflector system is greater than through the southern light barrier with an equivalent surface $3 F_{3}$ :

$n_{6}=Q_{n p 3} / Q_{n p 5 B}=0,86 \ldots 1,16 ; \Pi \Gamma=Q_{n p 3} / Q_{n p 5 \Gamma}=2,01 \ldots 2,72$.

The heat sink functions as a heater. The temperature of the heat receiver varies in proportion to the intake of solar radiation and the air temperature in the room.

In the period from 10-11 hours and up to 15 hours the temperature of the air in the room exceeds the normative value $t_{i}=20^{\circ} \mathrm{S}$. During this period, it becomes necessary to accumulate an excess of heat from solar radiation.

The given temperature regime in the period of the minimum arrival of solar radiation and the lowest temperatures of the outside air allows us to predict the effectiveness of the system of reflectors installed on the north side of the building during the heating season.

\section{References}

[1] Imomov Sh. B., Kim VD, Khairiddinov BE, Dusyarov AS Thermal efficiency of flat reflectors installed on the north side of a building in passive solar heating systems. // Heliotechnika, 2003, N4, S. 39-44.

[2] Elizarov AG Heating and ventilation of buildings and structures of agricultural complexes. -M.: Stroiizdat, 1981, 239 p.

[3] Kim VD, Dusyarov AS, Kim VV Determination of the convective heat transfer coefficient on the external surfaces of solar plants // Heliotechnics. -Tashkent: Fan, 2004, №2, P. 27-30.

[4] JA Duffy, Beckman UA Thermal processes using solar energy. -M.: World, 1977, - 420 pp.

[5] Bogoslovsky V.N. Thermal regime of the building. -M.: Stroiizdat, 1979, 248 p.

*Corresponding author.

E-mail address: imomov-shuhrat@ rambler.ru 